\title{
FutureJournal
}

\section{Modelo de Negócio: as Operações de uma Distribuidora de Combustíveis no Complexo Industrial Portuário de Suape/PE}

\author{
Davi Lucas Arruda de Araújo \\ Professor de Pós graduação Lato Sensu da Universidade Presbiteriana Mackenzie, Brasil \\ davi_lucas89@hotmail.com \\ Dimária Silva e Meirelles
}

Professora do Programa de Pós Graduação em Administração de Empresas da Universidade Presbiteriana Mackenzie, Brasil dmeirelles@gmail.com

\section{Silvio Popadiuk}

Professor do Programa de Pós Graduação em Administração de Empresas da Universidade Presbiteriana Mackenzie, Brasil spopadiuk@gmail.com

\section{Bárbara Ilze Semensato}

Doutorado em Administração pela FEA - Faculdade de Economia Administração e Contabilidade da USP - Universidade de São Paulo, Brasil barbarailze@gmail.com

\section{Paolo Edoardo Coti-Zelati}

Professor de Administração de Empresas em cursos de Lato Sensu da USCS - Universidade Municipal de São Caetano do Sul, Brasil coti_zelati@outlook.com

\section{RESUMO}

O objetivo principal desta pesquisa consiste em identificar as dimensões do modelo de negócios utilizando o Canvas Business Model, da empresa ALFA Combustíveis no Complexo Industrial Portuário de Suape/PE. O estudo é de natureza exploratória e foi desenvolvido mediante uma pesquisa de campo qualitativa. A coleta de dados ocorreu por meio de entrevistas semiestruturadas considerando como sujeitos de pesquisa profissionais dessa distribuidora que atuam na base de operações do complexo de Suape/PE. No tratamento, interpretação e análise dos resultados acerca dos dados coletados, foi utilizada a técnica de categorização. Os resultados revelam que a empresa, no que diz respeito à oferta de valor, desenvolve ações para melhoria da eficiência na prestação do serviço. No que tange à infraestrutura, pessoas com expertise, atividades bem alinhadas e política de custos bem definidas são necessárias para o desenvolvimento desse tipo de negócio. No que 


\section{FutureJournal}

se refere aos clientes, a segmentação em postos revendedores, o desenvolvimento de softwares que auxiliam no relacionamento com os clientes, projetos de entrega de produtos em tempo hábil e delimitação das fontes de receitas em função das atividades que são executadas na base configuram o modelo de negócio de uma distribuidora de combustíveis.

PALAVRAS-CHAVE: Modelos de negócios. Distribuição de combustíveis. Oferta de valor. Infraestrutura. Clientes.

\section{Business Model: The Operations of a Fuel Distributor in Industrial Port Complex of Suape/PE}

\section{ABSTRACT}

The main objective of this research is to identify the dimensions of the business model using the Canvas Business Model of the company ALFA Fuel in the Industrial Port Complex of Suape/PE. The study is exploratory and was developed through a qualitative field research. The data were collected through semi-structured interviews considering as research subjects of professionals from this distributor that work at the operational of the Suape/PE complex. Regarding the treatment, interpretation and analysis of the results on the data collected, the categorization technique. The results reveal that the company, in respect of its value proposition, develops initiatives to improve efficiency in service delivery. Regarding infrastructure, expert professionals well aligned activities and a well-defined cost policy is needed to develop this type of business. In reference to customers, segmentation of service stations, the development of software that assist in building customer relationships, on time product deliveries and delineation of revenue sources at the operational base configure the business model of a fuel distributor.

KEY-WORDS: Business models. Fuel distribution. Value proposition. Infrastructure. Customers. 


\section{FutureJournal}

\section{INTRODUÇÃO}

O Brasil vivencia um período de grande demanda por combustíveis, e o desempenho de suas distribuidoras registrou saldo mais do que positivo. Enquanto a expansão do PIB ficou no patamar de $0,1 \%$, as vendas de combustíveis pelas filiadas ao Sindicato Nacional das Empresas Distribuidoras de Combustíveis e de Lubrificantes (Sindicom) mantiveram-se à frente do mercado e ultrapassaram a marca dos 100 bilhões de litros anuais, respondendo por $78,8 \%$ da oferta de combustíveis no país. Na contramão do fraco desempenho da economia, as associadas ampliaram suas vendas em 6,3\%, alcançando 104,8 bilhões de litros, enquanto a comercialização no conjunto do setor, de aproximadamente 133 bilhões de litros, evoluiu 5,7\% em 2014 (Sindcom, 2015). Esses resultados são decorrentes do estímulo ao crédito para as famílias, por incentivos temporários via desoneração de impostos e por meio da política de controle da inflação mediante o represamento do reajuste de combustíveis.

No Complexo Industrial Portuário de Suape/PE, as diversas distribuidoras de combustíveis montam estruturas específicas, às quais denominam de base. Essas bases ficam alocadas em grandes terminais responsáveis, em essência, pelo armazenamento e carregamento de veículos das distribuidoras. As atividades voltadas às distribuidoras são exclusivamente: i) comercialização de combustíveis (etanol, gasolina e diesel); ii) emissão de notas fiscais sobre a venda dos produtos; iii) conferência da capacidade e das condições dos veículos; iv) orientação aos clientes bandeirados com a marca da distribuidora; e v) planejamento das rotas de entrega.

Uma das empresas aí instaladas é a distribuidora ALFA Combustíveis, cujas operações tiveram início em 1996 no Complexo Industrial Portuário de Suape/PE. A empresa ingressou no negócio de combustíveis motivada pela oportunidade dos acionistas, que perceberam, por meio da abertura do mercado daquele momento, a necessidade de garantir abastecimento de combustíveis com qualidade e segurança aos postos de pequeno e médio portes, situados 


\section{FutureJournal}

principalmente em municípios do interior e periferias das grandes cidades. Dessa forma, a empresa vem ao longo dos anos posicionando-se como uma das maiores distribuidoras independentes do Brasil e atuante nos estados do Pará, Maranhão, Ceará, Piauí, Rio Grande do Norte, Paraíba, Pernambuco, Alagoas, Sergipe, Bahia, Tocantins, Goiás, Minas Gerais e Espírito Santo e também no Distrito Federal.

Para entender como essa distribuidora opera nesse complexo, recorre-se à literatura de modelos de negócios, analisados à luz do modelo e das proposições estabelecidas por Osterwalder \& Pigneur (2010), segundo os quais um modelo de negócio descreve a lógica de como uma organização cria, entrega e captura valor. Logo, essa descrição deve ser feita mediante nove blocos constitutivos, que abarcam as quatro áreas fundamentais de um negócio: i) clientes; ii) oferta; iii) infraestrutura e iv) viabilidade financeira. Na ótica de Osterwalder \& Pigneur (2010), a área de clientes é composta das dimensões relacionamento com clientes, segmentos de clientes e canais. Na oferta, tem-se presente a dimensão da proposta de valor. A área de infraestrutura, por sua vez, abarca as atividades-chave, as redes de parceiros e os recursos-chave. E, por fim, no que tange à área financeira, estão presentes as dimensões da estrutura de custos e as fontes de receitas. Dessa forma, tomando-se como referência a literatura de modelos de negócios e tendo como finalidade explorar o contexto de distribuidoras de combustíveis, tem-se a seguinte questão de pesquisa: Quais dimensões do modelo de negócio presentes na empresa ALFA contribuem para sua atuação competitiva no segmento de distribuição de combustíveis?

Portanto, o objetivo principal deste estudo consiste em identificar quais dimensões do modelo de negócios, baseado no Canvas Business Model, estão presentes na distribuidora ALFA Combustíveis para operar na estrutura do Complexo Industrial Portuário de Suape/PE. Dessa forma, os objetivos específicos são: i) compreender as características do modelo de negócios acerca do bloco constitutivo oferta de valor; ii) compreender as características do modelo de negócios acerca do bloco constitutivo infraestrutura; iii) compreender as características do modelo de negócios acerca do bloco constitutivo clientes. No 


\section{FutureJournal}

\section{FUTURE STUDIES RESEARCH JOURNAL:}

TRENDS AND STRATEGIES

escopo desta pesquisa, portanto, não se aborda o bloco constitutivo viabilidade financeira, o que constitui, portanto, uma das limitações da pesquisa.

Justifica-se a realização desta pesquisa em função de a temática modelos de negócios receber, atualmente, grande atenção da literatura no campo da estratégia empresarial, e em razão de o estudo da distribuição de combustíveis ser um assunto pouco explorado sob a perspectiva da gestão. Além disso, com este trabalho, pretende-se elucidar como as empresas do segmento de combustíveis, instaladas em grandes complexos industriais, alocam seus recursos, capacidades, competências e ativos na distribuição dos principais produtos desse tipo de organização.

\section{REFERENCIAL TEÓRICO}

\subsection{DIMENSÕES DO MODELO DE NEGÓCIOS: CANVAS BUSINESS MODEL}

A principal função do modelo de negócio é fornecer a descrição genérica de como uma empresa cria e distribui valor, ela mesma, de modo lucrativo. Para tentar compreender o papel dos componentes (peças) do modelo de negócio, a cadeia de valor é o objeto de estudo frequentemente citado, como exposto por Amit e Zott (2001) e Magretta (2002). A sustentação teórica desses autores passa por conceitos de que modelos de negócios são variações na cadeia de valor genérica, que existe em todos os negócios, e de que a cadeia de valor integra processos (atividades) que viabilizam as transações.

A análise da cadeia de valor é um método para decompor a firma em atividades estrategicamente importantes e permitir compreender quais são os impactos em custo e valor, dirigindo, portanto, muita atenção às unidades de custo (Porter, 1998; Stabell \& Fjeldstad, 1998). Todavia, a cadeia de valor é um conceito eminentemente interno, operacional, que não capta as relações da firma com fornecedores, clientes e parceiros em geral. Essa articulação com o ambiente externo é fundamental na apropriação do valor criado. Conforme destaca Teece (2010), a essência de um modelo de negócio está na definição da maneira pela qual a empresa entrega valor para os clientes, induz os clientes a 


\section{FutureJournal}

pagar pelo valor e converte esses pagamentos em lucro. Com isso, o conceito de modelo de negócio vai além da cadeia de valor e deve considerar, portanto, tanto a organização interna (cadeia de valor) quanto a externa (rede de valor) (Bertrand, Disle, Gonthier-Besacier, Périer \& Protin, 2012).

A abordagem de modelos de negócio demanda uma visão holística sobre a lógica de negócio de uma organização, em conformidade com as proposições de Osterwalder (2006) e de Osterwalder e Pigneur (2010). De acordo com o modelo proposto por esses autores, um modelo de negócio é constituído por nove blocos, que descrevem a lógica de como uma empresa pretende aumentar sua lucratividade. Na Figura 1, apresenta-se a configuração desses blocos.

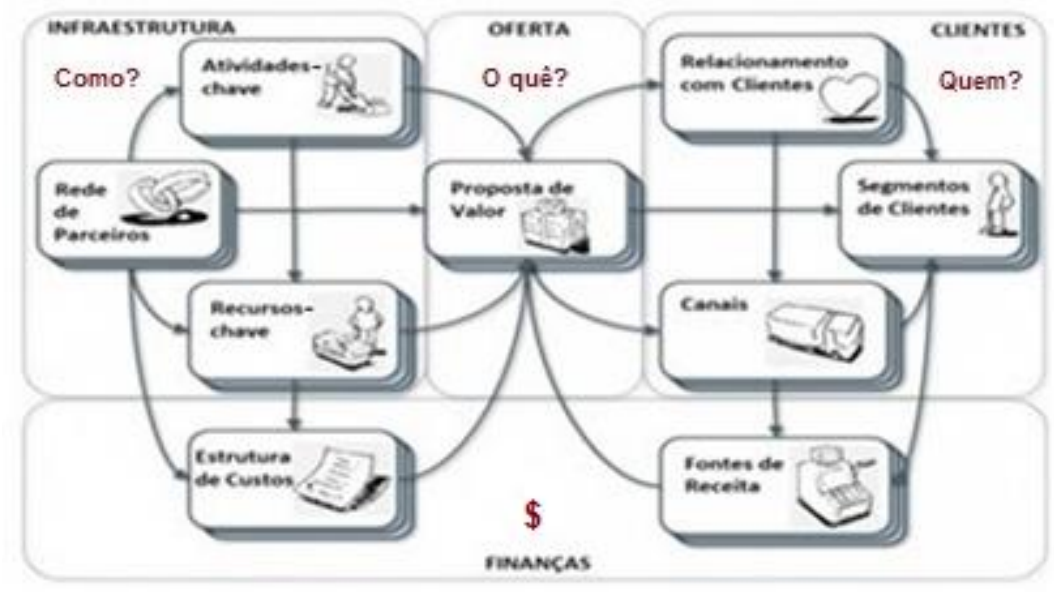

\section{Figura 1: Dimensões do modelo de negócios}

Fonte: Adaptado de Osterwalder e Pigneur (2010)

O objetivo das redes de parcerias é a complementação da proposição de valor e a melhoria das posições competitivas dos parceiros, envolvendo motivações como a otimização para obtenção de economias de escala, a redução de riscos e incertezas e a aquisição de recursos e atividades específicos (Osterwalder \& Pigneur, 2010). Nesse aspecto, Itami e Nishino (2010) fazem referência à proposta da "formatação" terceirizada, a qual funciona como um sistema de controle externo, ao mesmo tempo em que as empresas - interna e externamente - conseguem informações sobre tecnologias e custos. A vantagem 


\section{FutureJournal}

derivada da utilização desse modelo de desagrupamento de atividades seria a redução dos custos diretos de produção e do custo do capital investido.

Conforme Osterwalder (2006), as atividades-chave estão vinculadas aos recursos, quer sejam próprias ou de parceiros; consequentemente, o valor vincula-se aos processos e às atividades internos e externos. Na categorização proposta por Osterwalder e Pigneur (2010), as atividades podem ser: a) produção; b) solução de problemas e c) plataforma/rede. A produção consiste em realizar as atividades do projeto, ou seja, a manufatura e a entrega de um produto em quantidades substanciais e/ou de qualidade superior, sendo este o modelo de negócios dominante para os fabricantes. A solução de problemas propõe-se a fornecer novas propostas para os clientes, o que requer gestão do conhecimento e treinamento contínuos. A plataforma/rede é resultado de uma rede de parcerias, associações, cooperação e alianças entre as empresas que contribuem para o funcionamento do modelo de negócio.

Inspirado na definição de recursos de Penrose (1959), Osterwalder e Pigneur (2010) afirmam que recursos-chave podem ser físicos, financeiros, intelectuais ou humanos e podem ser detidos ou arrendados pela companhia ou adquiridos de parceiros-chave. Reportando-se aos recursos-chave como componente essencial na configuração de valor dos blocos constitutivos do modelo de negócios, Osterwalder (2006) expõe que cada proposição de valor deve ser relacionada com cada recurso-chave, analisando-se e entendendo-se as relações causais dos recursos-chave com os canais de relacionamento, com os relacionamentos com os clientes, com os segmentos de clientes e com os fluxos de receitas.

Sobre o bloco estrutura de custos, Stabell e Fjeldstad (1998) afirmam que o comportamento dos custos das atividades que criam valor é decorrente de fatores estruturais, definidos como drivers de custos. Importante seria a plena identificação desses fatores estruturais, gerando conhecimento que permita a avaliação do comportamento dos custos e dos custos econômicos das atividades de valor. Como resultado, a exploração e a formatação desses fatores estruturais é uma fonte de vantagem competitiva. De acordo com Osterwalder e Pigneur (2010), os modelos de negócios podem ser baseados em custos ou em valor. Os 


\section{FutureJournal}

primeiros focam a minimização de custos sempre que possível. O propósito é criar e manter a estrutura de custos a mais enxuta possível, utilizando proposições de valor de baixo preço, a máxima automação e a terceirização extensiva.

Conforme Osterwalder e Pigneur (2010), a proposição de valor envolve o entendimento da natureza do problema do cliente e como prover a solução adequada. A partir de um estudo conduzido na Europa e nos Estados Unidos, Anderson, Narus e Van Rossum (2006) constataram ser muito difícil encontrar exemplos de proposições de valor que façam sentido para os clientes. Os autores assinalam que a equação de valor expressa como enxergar as diferenças de desempenho entre uma oferta e a próxima melhor opção e como traduzi-la em ganhos.

Os relacionamentos com clientes, por sua vez, são os relacionamentos que uma empresa estabelece com segmentos de clientes específicos. A aquisição e a retenção dos clientes advêm dos relacionamentos positivos, influenciando decisivamente suas experiências, e podem apresentar como resultado o aumento das vendas. A categorização dos relacionamentos, na proposta de Osterwalder e Pigneur (2010), inclui: assistência personalizada, assistência personalizada dedicada, serviços automatizados, comunidades e criação conjunta.

O bloco segmento de clientes visa definir os clientes ou organizações que uma empresa possui como alvo. Uma organização deve tomar uma decisão consciente sobre quais segmentos atender e quais segmentos ignorar, uma vez que, tomada a decisão, o modelo de negócio pode ser cuidadosamente projetado, baseado em um forte entendimento acerca das necessidades específicas do cliente. Conforme Osterwalder e Pigneur (2010), uma organização serve um ou vários segmentos de clientes se suas necessidades requererem ofertas distintas, diferentes canais, diversos tipos de relacionamentos e lucratividades diferentes; e se os clientes estiverem aptos a pagar mais por ofertas distintas.

Os canais são pontos de contato com os clientes, tendo um papel importante em sua experiência de compra e são também responsáveis por difundir informações e conhecimentos sobre produtos e serviços de uma 


\section{FutureJournal}

companhia. A prestação de suporte pré e pós-venda para os clientes é elemento presente nos canais e também integram a proposição de valor da empresa, permitindo que os clientes possam comprar produtos e serviços customizados (Osterwalder \& Pigneur, 2010).

Por fim, a geração do fluxo de receitas pode advir da venda de ativos, da taxa de uso, das taxas de subscrição, de empréstimos, de aluguéis e arrendamentos, do licenciamento, da corretagem e da propaganda. As receitas podem, portanto, ser oriundas de transações temporárias ou recorrentes, dependendo do tipo de relacionamento com o cliente e da força de cada uma das partes desse relacionamento. O fluxo de receitas envolve mecanismos variados de precificação, variando de listas de preços fixos a diferenciados, ou dinâmicos (Lecocq, Demil, \& Warnier, 2006; Teece, 2007; Osterwalder \& Pigneur, 2010).

\section{PROCEDIMENTOS METOdOLÓgICOS}

Na seção de procedimentos metodológicos, abordam-se o método e a natureza da pesquisa, apresentam-se os sujeitos, o modo como os dados foram coletados e a técnica de análise adotada.

\subsection{MÉTODO E NATUREZA DA PESQUISA}

O método desta pesquisa é qualitativo. Esse tipo de método é composto por técnicas que não utilizam mecanismos estatísticos como suporte para o processo analítico do problema estudado (Richardson, 1999). Além disso, tem por finalidade avaliar a representatividade de um conjunto de sujeitos que faz parte da pesquisa e considera sua justificativa quando se pretende compreender determinado fenômeno, explorar a complexidade de um problema e classificá-lo (Merriam, 1998). Esta pesquisa é de natureza exploratória. Para Godoy (1995), esta é a mais adequada quando o pesquisador lida com problemas pouco conhecidos, cuja busca se apoia na compreensão do fenômeno como um todo. Ainda, o principal valor para esse tipo de estudo é o entendimento das reais 


\section{FutureJournal}

interações entre os sujeitos, os sentidos e os processos que configuram os cenários da vida organizacional na realidade.

\subsection{SUJEITOS DA PESQUISA E COLETA DE DADOS}

As entrevistas foram realizadas no local de trabalho dos indivíduos, em horário de expediente, com o objetivo de facilitar a participação de todos os potenciais sujeitos da pesquisa. As gravações foram permitidas pelos sujeitos. Entretanto, durante o processo de negociação para a realização das entrevistas, os autores argumentaram que a pesquisa não era uma avaliação sobre a organização, tratava-se apenas um estudo de caráter acadêmico com a finalidade de compreender suas percepções acerca dos assuntos relatados. As gravações foram transcritas em forma de texto e, a partir desse procedimento, as primeiras reflexões puderam ser realizadas pelos autores.

Por ser uma pesquisa qualitativa, para Merriam (2009), não existe uma delimitação rígida em relação ao número adequado dos sujeitos da entrevista. Em outras palavras, esse é um dado que pode sofrer alterações ao longo do processo, seja pela necessidade de complementação de informações, seja pelo esgotamento, à medida que as respostas passam a apresentar redundâncias.

Na concepção de Flores (1994), a técnica de entrevista visa coletar dados verbais e a partir dos relatos compreende e interpreta como a realidade é vivenciada pelos próprios entrevistados. Foram realizadas quatro entrevistas no local de trabalho, com quatro profissionais que exercem funções na base operacional da empresa instalada no Complexo Industrial Portuário de Suape/PE. Foram escolhidos para participar da entrevista o diretor-geral, o gerente de operações, o gerente comercial e a analista de faturamento. Esses profissionais são diretamente responsáveis pela gestão das atividades voltadas à distribuição de combustíveis da organização. Porém, como forma de manter o anonimato, não se identificaram os sujeitos nesta pesquisa. Por isso, utilizaram-se as siglas E1, E2, E3 e E4 para referência aos sujeitos citados.

A coleta de dados foi realizada por meio da aplicação aos entrevistados de um roteiro (questionário semiestruturado) com 15 perguntas específicas 


\section{FutureJournal}

acerca do tema modelos de negócios. Envolveu também a busca de dados do setor, documentos fornecidos pelas empresas e observações in loco dos autores. Os documentos foram oriundos dos projetos, anuários e outros relatórios de desempenho das empresas e do segmento. As entrevistas individuais com os gestores registraram um tempo médio de 60 minutos, nos escritórios da empresa, conforme o protocolo de pesquisa, e foram gravadas digitalmente.

\subsection{TÉCNICA DE ANÁLISE DOS DADOS}

Para a análise de dados, esta pesquisa fundamenta-se nos conceitos de categorização de Flores (1994). De acordo com essa abordagem, a organização e a análise de dados são feitas por temas definidos como relevantes ao pesquisador. Os dados qualitativos podem ser produzidos em uma entrevista, em uma reunião, em contato interpessoal ou em documentos escritos, comportamentos e eventos coletados nas notas de campo. Porém, os dados qualitativos também são fotografias, filmes e gravações feitas nos contextos estudados que contribuem para o fornecimento de informações para a pesquisa, sobretudo os objetos, sua distribuição e sua utilização (Flores, 1994).

\section{ANÁLISE DOS DADOS}

Nesta seção, são abordadas as análises acerca dos resultados desta pesquisa. Inicialmente apresentam-se as análises do bloco oferta, do bloco infraestrutura (composto das categorias atividades-chave, rede de parceiros, recursos-chave e estrutura de custos) e do bloco clientes (composto das categorias segmento de clientes, relacionamento de clientes, canais e fontes de receitas).

\subsection{ANÁLISE DO BLOCO OFERTA}

No entendimento de Baden-Fuller e Morgan (2010), as receitas funcionam com base em tecnologias e ingredientes conhecidos, os quais podem ter valor somente para aquela situação. Em outras palavras, mudar a receita pode implicar uma mudança de valor no modelo de negócio. Em contrapartida, para Osterwalder e Pigneur (2010), a proposição de valor descreve produtos e serviços que criam valor para um segmento particular de clientes. Esse 


\section{FutureJournal}

delineamento no segmento de combustíveis pode ser observado nas entrevistas realizadas. O relato dos entrevistados da empresa ALFA Combustíveis engloba alguns aspectos da proposição de valor para o segmento. Entretanto os entrevistados voltam-se para aspectos tais como preço, assistência comercial, qualidade, estrutura, etc.

"Basicamente eu acho que é a relação da distribuidora com o cliente final, com o revendedor. Nós somos distribuidores, então a gente precisar entender a necessidade, tanto a comercial, que é importante com relação a preço, como a assistência em avaliar com mais critério e benevolência limite de crédito, prazo, condição, como ela pode se encaixar dentro dessa estrutura. Porque na verdade é uma operação que precisa de uma envergadura, você precisa ter uma certa capacidade financeira na revenda como na distribuição porque o teu vizinho faz a mesma coisa que você e um centavo na bomba faz uma grande diferença (...)." (E1)

"Tanto no serviço, como no atendimento, como na prestação de serviços suplementares para o cliente no ponto, faz uma diferença. A gente tem um departamento que orientamos o revendedor como que atende, como vende, possibilidade de abrir uma loja de conveniência para agregar valor. Já que a estrutura está montada, para quanto mais serviço se presta para o cliente, mais ele se fideliza e vai parar ali com você". (E3)

"(...) esse é o sinal que nós temos para irmos em frente para avaliarmos que estamos no caminho certo e para ficarmos atentos que não podemos parar. Precisamos manter esse foco do cliente (...)." (E3)

\subsection{ANÁLISE DO BLOCO INFRAESTRUTURA}

\subsubsection{Atividades-chave}

As atividades-chave descrevem as coisas mais importantes que se devem fazer para que o modelo de negócio funcione, requerendo ações que atinjam os mercados (Osterwalder \& Pigneur, 2010). O segmento de combustíveis apresenta diversas atividades consideradas essenciais: i) vendas de combustíveis - etanol, gasolina, diesel e outros; ii) emissão de notas fiscais; iii) conferência da capacidade e condições dos veículos; iv) orientação aos clientes conveniados (bandeirados com a marca da distribuidora); v) planejamento das rotas de entrega; e vi) controle de qualidade. Por sua vez, a empresa é cliente do terminal e do Complexo Industrial Portuário de Suape/PE, sendo alocada dentro dessa estrutura, de modo a contratar os serviços de armazenagem e 


\section{FutureJournal}

carregamento dos veículos. Os relatos dos entrevistados apontam a importância dessas atividades para o negócio da empresa.

"Existe todo um time voltado a isso, o departamento comercial é muito envolvido com o departamento de qualidade, com o departamento de recursos humanos. Há algumas ações pontuais em determinadas épocas do ano como convenções, onde a gente traz todos os gerentes de vendas do Brasil todo e faz workshop aqui na matriz em que a gente foca muito no atendimento por excelência, na qualidade e na motivação do time em prestar um serviço de excelência porque, preço por preço, todo mundo tem mais ou menos a mesma coisa, então, assim, a atenção diária, o contato, a visita, uma assistência e é isso ai que vai fazer a diferença e que vai mostrar os resultados e também muito focado nas metas. Cada time tem sua meta, cada gerente precisa apresentar seus resultados e essa união aí do comercial com logística com qualidade tem sido vencedora." (E1)

"Existem várias atividades que são consideradas essenciais, contudo, do ponto de vista operacional, o que mais nos atentamos é com a comercialização em si dos combustíveis, principalmente do etanol, da gasolina e do diesel, a emissão de notas fiscais sobre a venda dos produtos, a conferência da capacidade e as condições dos veículos por meio de um checklist bem rigoroso, a orientação aos clientes conveniados, ou seja, os que são bandeirados com a marca da distribuidora, o planejamento das rotas de entrega, também uma atividade que temos bastante atenção, pois precisamos aproveitar a máxima capacidade de entrega do veículo e otimizando as rotas e também o controle de qualidade do produto que, mesmo o terminal fazendo esse procedimento diariamente, a nossa empresa tem um laboratório in loco no terminal que garante ao nosso cliente a qualidade do combustível que ele está comprando." (E2)

Segundo Shafer, Smith e Linder (2005), as escolhas e implicações operacionais incluem a análise das relações de causa e efeito das estratégias selecionadas, permitindo até a comparação com outros modelos de negócio simultaneamente antes de se chegar a uma definição do melhor modelo a ser adotado.

\subsubsection{Rede de parceiros}

A externalização das atividades de valor depende da criação de parcerias significativas em áreas que tenham relevância estratégica, estabelecendo-se vínculos com parceiros, tecnologias e até indústrias (Möller \& Törrönen, 2003). As funções diretas de uma relação de fornecimento podem ter efeito imediato na lucratividade, pois suportam os processos operacionais do cliente e sua excelência operacional (Ritter \& Walter, 2012). Os trechos dos entrevistados fazem referência a algumas parceiras existentes entre a distribuidora e outras 


\section{FutureJournal}

empresas, como também à dificuldade em se estabelecerem parcerias em razão das características do segmento e do tipo de atividade que desempenham.

"O grupo tem vários segmentos, a gente atua em outras áreas que nem se envolvem muito com a parte de derivados, mas a gente não tem associação com nenhum outro player do segmento. Dependendo da oportunidade, dependendo do momento, é possível às vezes você se juntar com um player maior ou com um player menor por determinada conveniência. Às vezes você tem um time que atua no Nordeste e tem outro time que atua no Sul e estrategicamente se decide que, por exemplo, ser menor em uma determinada região possibilita ganhar mais envergadura tendo mais escala e controle. Quero dizer que é muito comum se juntar, se fundir, se associar com algum outro player que traga para sua companhia alguma expertise que você não tenha. Sua empresa é boa em determinado segmento, outra empresa tem expertise em outras atividades e aí vocês se juntam e ficam maior. Aí com relação a tudo, mas, como te falei, a gente não tem nenhuma associação ou envolvimento com nenhum outro player." (E1)

"(...) necessariamente, não temos nenhum envolvimento, nem projeto nem intenção. Nada que não estejamos abertos para conversar para entender se é bom para nós, se é bom para a empresa, tá? Mas, assim, hoje podemos dizer que tocamos a carreira solo." (E1)

"Basicamente nossos principais parceiros são transportadoras ou profissionais autônomos que são contratados pelos clientes independentemente do serviço de entrega que já prestamos (...)." (E3)

Osterwalder e Pigneur (2010) destacam a importância das parcerias nos modelos de negócio, em diferentes tipos, com o objetivo de gerar economias de escala, reduzir riscos e incertezas e, principalmente, adquirir recursos e desenvolver atividades singulares. A empresa pode ser capaz de criar relacionamentos singulares com quaisquer partes ou até com consumidores finais.

\subsubsection{Recursos-chave}

Os recursos-chave, que podem ser humanos, financeiros, intelectuais ou físicos, englobam os ativos essenciais para o funcionamento do modelo de negócio (Osterwalder \& Pigneur, 2010). A utilização estratégica desses recursos pode representar como as empresas atingem os mercados-alvo, como se relacionam com esses mercados e como geram lucros. Embora a empresa necessite adquirir e construir os recursos à sua disposição para seu uso, é necessário identificá-los e acessá-los para compreender quais deles a empresa 


\section{FutureJournal}

possui e quais devem ser adquiridos. Os trechos dos sujeitos de pesquisa ressaltam o recurso humano como imprescindível, principalmente na base de operação. Além disso, ressaltam que o alinhamento entre os departamentos e a eficiência na operação de carregamento de veículos é fundamental para o sucesso desse modelo.

"Cada dia que passa, nós vamos tentando aprimorar o atendimento trazendo gente para o time que realmente tenha expertise, que realmente conheça 0 mercado para poder atender melhor a demanda dos clientes que porventura estejam insatisfeitos com qualquer outra distribuidora ou qualquer outro fornecedor. Então, acho que esse contato diário e meio que pessoal com o posto revendedor é que faz a diferença e com o passar do tempo a gente está equipando a companhia com pessoas que tenham habilidade e experiência no setor e que venham a somar e passar confiança ao posto revendedor, porque, a partir do momento que você entra em uma praça nova, você é um forasteiro e para conquistar um cliente novo é preciso passar segurança, comprometimento com entrega, com qualidade, com condição de preço, de competitividade com concorrente. Eu acho que isso é um dos grandes recursos da companhia." (E1)

"Não adianta ter o maior sistema, não adianta ter o melhor software, não adianta ter a maior estrutura, não adianta operar em um número maior de terminais e infinitas distribuidoras filiadas se ela não tem capital humano (...). Sem dúvida, nesse segmento, a estrutura e o planejamento são condições necessárias, contudo, se não houver um grande alinhamento entre os departamentos, desde as vendas até a ponta, que fica nas bases espalhadas pelo Brasil, muito provavelmente haverá problemas na efetivação da venda e entrega ao cliente (...)." (E2)

\subsubsection{Estrutura de custos}

Stabell e Fjeldstad (1998) evidenciam a importância relativa e o papel que os drivers de custos podem assumir diferentemente entre as firmas, ressaltando que os drivers mais importantes são as decisões políticas feitas para o produto e as escolhas de segmentos quando a firma está estabelecida ou se reposicionando. Os sujeitos da pesquisa ressaltaram que os custos da estrutura, a armazenagem do produto nos tanques dos terminais, a prestação do serviço e o próprio custo do combustível destacam-se no que se refere à estrutura de custo desse modelo de negócio.

"(...) cada um monta sua estrutura, seu centro de custo, tenta enxugar o máximo possível para se ter resultado, como qualquer segmento. Como os preços são muito parecidos, o que acaba fazendo a distribuidora ganhar mercado, do ponto de vista de custo, ainda é equacionar os números no atendimento e na prestação de serviço. Vale dizer que, basicamente, o preço do 


\section{FutureJournal}

produto tem um alto impacto representando cerca de $60 \%$ dos custos, pois é o insumo em si. E a estrutura depende da estratégia, você é que vai definir como deseja colocar sua estrutura. Se você abre mais pontos de vendas com uma estrutura só, você vai conseguindo diluir, vai ganhando escala diluindo os custos com as novas posições; mas isso depende muito da estratégia, muito de oportunidades, depende muito de uma série de fatores que contribuem para perder ou ganhar mercado." (E1)

"Outro custo que tem é o próprio custo de comercialização. Que tá também, em volta de, despesas de comercialização, que é Marketing, despesas de comissão, ele está por volta de 6 a 7\%. Além disso, temos outro indicador que são os custos comerciais, ou seja, quanto estamos gastando sobre o valor de venda. (...). Dentro do segmento de combustíveis, um dos itens que mais pesam é a estrutura. Estrutura e instalações representam por volta de 30 a $40 \%$ do custo da operação (...). Outro indicador de custo é o custo do produto medido por metro cúbico. Além do custo de armazenagem, sendo outro custo importante pra gente (...)." (E4)

Nos modelos focados no valor, as empresas preocupam-se menos com as implicações de custo de um projeto particular de modelo de negócio e mais com a criação de valor. Tais modelos são caracterizados por proposições de alto valor e alto grau de serviços personalizados. Além disso, Osterwalder e Pigneur (2010) dividem os custos em fixos e variáveis e atentam para as economias de escala (a expansão gera mais retornos) e de escopo (o uso de atividades e recursos para diversos serviços e produtos).

\subsection{ANÁLISE DO BLOCO CLIENTES}

\subsubsection{Segmento de clientes}

O foco em mercados refere-se ao atendimento das necessidades particulares de um segmento específico (Nourse \& Roulac, 1993). Osterwalder e Pigneur (2010) ressaltam a importância da definição dos segmentos de atuação, pois um modelo deve ser configurado para o atendimento das necessidades específicas dos clientes. Os sujeitos desta pesquisa apontam que, na categoria segmento de clientes, a distribuidora concentra-se apenas para atender as necessidades dos postos revendedores, sejam estes bandeirados ou não. Isso se dá em função de os postos serem os principais clientes desse tipo de atividade. 


\section{FutureJournal}

Além disso, os entrevistados relataram, de forma genérica, como a empresa avalia alguns critérios para abrir uma filial em uma nova região.

"Existe um critério e algumas regras que precisa se adequar para você ostentar a nossa bandeira, a nossa marca desde a análise de crédito até o teu potencial, volume, o que você pode crescer, qual sua galonagem hoje, o que você pode acrescentar aí no futuro. Então, assim é uma avaliação, onde a gente realmente pensa no futuro daqui a um ano, daqui a dois, daqui a cinco, ou seja, como você pode estar e, em cima de uma série de fatores, a gente vai estabelecendo uma relação comercial." (E1)

"A gente é focado exclusivamente na distribuição para postos revendedores. A gente não explora, não refina, não armazena. A ALFA distribuidora possui o foco de distribuição. (...) quando a gente identifica uma nova praça que a gente vai abrir uma nova filial, existe todo um estudo de mercado, da demanda, da necessidade, de quem está trabalhando, quais são as distribuidoras que estão lá, qual o potencial local de consumo daquela determinada região para a gente desenvolver um trabalho com a finalidade de consolidar a marca já que temos posições em diversos lugares do Nordeste, então, o mercado já entende como você trabalha, a seriedade, o comprometimento com qualidade, entrega, suprimentos de produtos e então, depois de uma série de avaliações, buscamos definir se merece abrir uma filial naquele lugar." (E2)

\subsubsection{Relacionamento de clientes}

O valor não advém tão somente do produto principal estritamente, mas de todo um elenco de interações fornecedor-cliente para o adequado fim desse produto (Grönroos, 2011). Assim como a quantidade de informações fornecida pelos clientes ou fornecedores por meio de relacionamentos de trabalho pode ser invocada para melhorar a efetividade de mecanismos deliberados de aprendizado para reconhecimento (Berghman, Matthyssens \& Vandenbempt, 2012). Nos trechos a seguir, os sujeitos apontam como ocorre o relacionamento da empresa ALFA Combustíveis com seus clientes (postos revendedores). Eles apresentam alguns projetos implementados junto com o terminal de combustíveis para melhorar a eficiência da operação e, consequentemente, a relação com o cliente no que diz respeito à entrega do produto. Vale também ressaltar que os sujeitos distinguem a relação com os clientes considerados bandeira branca e com os que ostentam a bandeira da empresa.

"Nas filiais estamos divididos em áreas e cada área tem uma gerência. São gerências regionais, que têm um time que cuida de cada cliente desde o atendimento, desde o pedido que é feito, da necessidade do suprimento até o acompanhamento diário no que diz respeito à atenção, se precisar fazer uma 


\section{FutureJournal}

reforma, mudar o layout do posto. A gente vai entendendo caso a caso quais são as necessidades, se a gente se adéqua, se a gente tem tamanho para isso, se o posto tem tamanho para ostentar a nossa bandeira e para consolidarmos uma relação comercial duradoura. Existem clientes que não têm compromisso com a empresa porque são bandeira branca e tem aqueles que já são bandeirados, que já estão contratados. Então esses aí já têm um compromisso com relação a volume e a suprimentos." (E1)

"Então tratar fica mais fácil. E estrategicamente em qualquer região de nossas bases operacionais, onde nós temos equipes de CIC, que é Central de Interação de Clientes (...). O Canal Cliente que o terminal disponibiliza para as distribuidoras, lá nós temos a programação com o programa de carga e o programa de descarga. Acessamos o programa de carga, acessamos a placa do veículo, o veículo tem que estar de acordo com toda a documentação, deve estar regulamentado, se tiver algum documento vencido no próprio sistema do Canal Cliente, ele já informa, o veículo ali é travado, não conseguimos programar o carro (...)." (E3)

Uma conceituação sistemática de criação de valor em relacionamentos de negócios deve refletir a natureza e as características do processo interativo no qual o valor do relacionamento é criado (Haas, Snehota \& Corsaro, 2012).

\subsubsection{Canais}

Segundo Osterwalder e Pigneur (2010), os tipos de canais podem ser diretos e indiretos. Canais diretos são representados pela equipe de vendas, pelas vendas por meio da internet e por lojas próprias. Canais indiretos caracterizam-se, por exemplo, como as lojas dos parceiros. Em ambos os tipos de canais, os autores entendem que é necessário que a empresa entenda como ela pode tornar-se conhecida pelos clientes, a maneira pela qual tem sua proposição de valor julgada pelos clientes, como permite aos clientes comprar produtos e serviços particulares, o modo pelo qual a proposição de valor chega aos clientes e a forma pela qual fornece suporte pós-vendas. Nos trechos das entrevistas, os sujeitos atentam para as ferramentas e estratégias estabelecidas com os clientes que possuem interesse em contratar a bandeira da empresa ALFA Combustíveis. Além disso, destacam um projeto que visa melhorar a entrega do produto.

"(...) a gente tem o nosso network, a carteira de cliente que já é consolidada, temos quase 20 anos de atuação, então, assim, não há ninguém que a gente não conheça no segmento. O titular do posto revendedor pode mudar de cadeira, mas, assim, o posto revendedor nós conhecemos bem. Então estamos 


\section{FutureJournal}

sempre atentos, as áreas sabem exatamente as movimentações, o que está acontecendo, quem está incorporando, quem está fechando, quem está assumindo, quem está comprando, quem está arrendando. Então, estamos muito juntos do posto revendo e conseguimos entender quais as movimentações $(\ldots) . "(\mathrm{E} 1)$

"Existe um modelo básico que é referência e regra. Claro que não serve para todos e basicamente ele funciona no mercado todo. Quem tem um comprometimento com uma distribuidora, as regras são mais ou menos as mesmas, independente se ele for do Sindicom ou se ela for uma regional. Em suma, o mesmo contrato que se aplica a um posto que tem uma galonagem pequena também se aplica a um posto com uma galonagem grande (...)." (E2)

"Nós implementamos um projeto recentemente, chamado Projeto Entrega Nota Dez e, quando você fala de Projeto Entrega Nota Dez é uma responsabilidade muito grande, então você imagina que hoje nós temos frotas próprias com caminhão padronizado, com a nossa marca, com a nossa logomarca, com o nosso treinamento, com o nosso cuidado, com o nosso acompanhamento de olho na legislação (...)." (E3)

\subsubsection{Fontes de receitas}

No entender de Osterwalder e Pigneur (2010), a geração do fluxo de receitas pode advir da venda de ativos, da taxa de uso, das taxas de subscrição, de empréstimos, de aluguéis e arrendamentos, do licenciamento, da corretagem, e da propaganda. Nesse sentido, as receitas podem advir de transações temporárias ou recorrentes, dependendo do tipo de relacionamento com o cliente e da força de cada uma das partes desse relacionamento. Além disso, destacam os combustíveis como a principal fonte de receita juntamente com os contratos firmados com clientes que celebram acordos para deter e operar sob a bandeira da distribuidora ALFA Combustíveis.

"Os fluxos de receita, até baseado no que te falei, são oriundos da distribuição. $A$ gente não tem nenhum envolvimento com outro segmento. É muito amplo esse segmento de derivados, de gás, de prospecção, de distribuição, enfim. Vale dizer também que somos muito regidos pelo mercado, combustível é commodity, e por isso não existe nem preço definido, nem caro, nem barato, ou seja, existe o mercado: dependendo de como o mercado se comporta, somos forçados a segui-lo. Não existe nenhuma estratégia predefinida, nós não temos muita marcha de manobra até porque o fornecedor é o mesmo, o revendedor é o mesmo, e por isso o que vai definir preço, custo final para revendedor acaba sendo a estrutura. Quanto mais pesada tua estrutura, mais custo e ai você tem que repassar isso para o preço, aí consequentemente você vai ter mais volume $(\ldots) . "(\mathrm{E} 1)$ 


\section{FutureJournal}

"Nossa principal fonte de receitas advém das vendas de gasolina, etanol e diesel. Acaba sendo um pouco complexo entrar nesse detalhe pois o negócio, mesmo tendo altos volumes de vendas, é muito definido para todas as distribuidoras. Outra fonte acabam sendo os acordos firmados com os clientes bandeirados (...)." (E4)

\section{DISCUSSÃO DOS RESULTADOS: O MODELO DE NEGÓCIO DA EMPRESA ALFA COMBUSTÍVEIS}

O Canvas Business Model foi concebido com o objetivo de descrever o valor ofertado por uma organização para um ou vários segmentos de clientes, bem como a arquitetura da organização e sua rede de parceiros para a criação, comercialização e distribuição desse valor, além dos aspectos de custos e capital, buscando assim gerar receitas lucrativas e sustentáveis (Osterwalder \& Pigneur, 2010).

No que concerne ao bloco oferta de valor, a empresa ALFA Combustíveis preocupa-se com a eficiência na prestação do serviço, destacando os aspectos de flexibilidade no processo de atendimento ao cliente, no atendimento customizado, visando atender às necessidades específicas, e na qualidade dos combustíveis comercializados pela empresa. Além disso, condições de pagamento, negociação de prazos e limite de crédito fazem parte da proposta de valor que a empresa oferta aos clientes devido à alta concorrência e ao produto em si (gasolina, diesel e etanol) não apresentar diferenças do ponto de vista de especificações entre distribuidoras.

Sobre o bloco infraestrutura, a empresa ALFA Combustíveis possui atividades-chave voltadas à logística, em que se preocupa com o planejamento de rotas de entrega; ao faturamento, que possui a finalidade de emissão de notas fiscais; às vendas, pois tem uma central que recebe os pedidos dos clientes e os encaminha para as bases operacionais; e à qualidade, possui um laboratório móvel que visita constantemente os clientes para verificar o grau de qualidade do combustível por eles comprado, juntamente com os testes que são realizados antes de qualquer venda.

Acerca dos recursos-chave, a empresa destaca-se por possuir frota própria, minimizando a dependência de outras transportadoras, e uma boa 


\section{FutureJournal}

FUTURE STUDIES RESEARCH JOURNAL:

TRENDS AND STRATEGIES

instalação alocada em um terminal que armazena seus produtos, que é responsável pelo controle de qualidade e planejamento de carregamento de veículos. Além disso, possui pessoas com experiência no setor, principalmente, nas bases operacionais, onde as rotinas são mais intensas, sendo de responsabilidade da empresa o alinhamento desses profissionais com os outros departamentos.

As parcerias, no contexto de uma distribuidora de combustíveis, aparecem em menor escala. Contudo, a empresa ALFA Combustíveis não deixa de ter ações de parceria com transportadoras que já têm relação estabelecida com clientes não bandeirados e precisam transportar determinados produtos. Os profissionais autônomos que trabalham com frete e são cadastrados junto à empresa para cumprir a programação de entrega e o terminal de combustível (mesmo sendo um serviço que a empresa contrata) atuam como grandes parceiros, colaborando para que a operação seja cumprida no tempo e no horário acordado com o cliente.

$\mathrm{Na}$ dimensão estrutura de custos, os principais custos com que a empresa ALFA Combustíveis se depara são os custos comerciais, direcionados às comissões de vendedores, feiras de divulgação, campanhas de marketing e desenvolvimento de ferramentas que melhorem a interação com o cliente. Os custos de armazenagem são significantes e onerosos à empresa, seu cálculo é feito por metro cúbico e a capacidade dos tanques é compartilhada com outras distribuidoras instaladas no mesmo terminal. O custo do produto é relevante devido ao produto ser uma commodity e o preço ser regulado pelo mercado. Os custos de instalações e estrutura são necessários devido à empresa estar presente em outras regiões do país e em processo de expansão para outros estados. Portanto, à medida que a empresa se consolida no mercado local é preciso investir, expandir e planejar uma política de custos no ambiente em que a empresa opera.

A respeito do bloco clientes, a empresa ALFA Combustíveis atua no segmento de postos revendedores, que podem ser bandeirados ou possuir bandeira branca. Contudo, em menor escala, comercializa seus produtos para as indústrias, para empresas do segmento automotivo e para grandes 


\section{FutureJournal}

transportadoras do estado de Pernambuco. A empresa, por meio de dois softwares denominados Canal Cliente e CIC, desenvolve mecanismos para estreitar a relação com seus clientes, sejam eles bandeirados ou não. Além disso, a utilização da internet (mediante acesso à plataforma intranet da empresa) e o projeto Entrega nota 10 são duas formas de estabelecimento de canais que a empresa ALFA Combustíveis aplica em seu modelo de negócios. Vale destacar que este último, além de trazer benefícios para o cliente do ponto de vista de o produto chegar antecipadamente ou no prazo estabelecido entre a empresa e o consumidor, acaba contribuindo para a construção de uma imagem positiva da organização no mercado local.

No que diz respeito às fontes de receitas, a captação realizada pela empresa ocorre por meio da comercialização de combustíveis como a gasolina do tipo: i) gasolina $A$; ii) gasolina $C$, iii) gasolina $C$ aditivada e iv) gasolina $C$ premium. A comercialização do etanol do tipo anidro e hidratado também se caracteriza como uma fonte de receita significativa, juntamente com a comercialização do diesel em suas variantes S500 e S10.

Para Morris, Schindehutte e Allen (2005), o desenvolvimento de modelos de negócios tem implicações nos processos internos e de infraestrutura a fim de que a organização crie valor. Os autores destacam as variáveis de decisão, entre elas os métodos de prestação de serviços, fluxos de logística, administrativo e financeiro, além dos processos de gestão do conhecimento. Portanto, utilizandose o Canvas Business Model, é possível observar, em um contexto geral, as ações para a oferta de valor, para o bloco de infraestrutura e para o bloco dos clientes, que constituem o modelo de negócio da empresa ALFA Combustíveis (Figura 2), construído em função das entrevistas realizadas com os sujeitos desta pesquisa. 


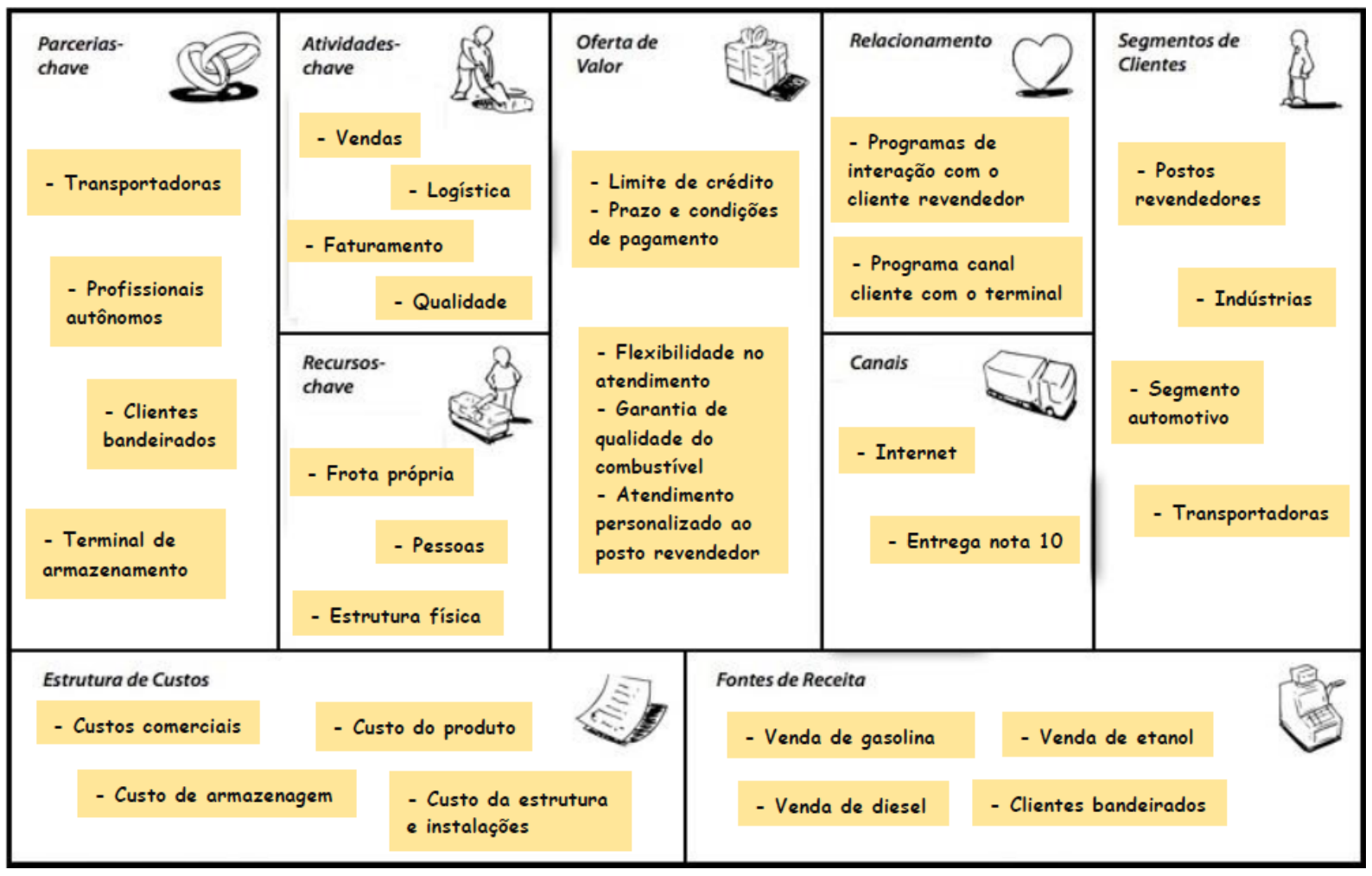

Figura 2: Canvas Business Model da empresa ALFA Combustíveis

Fonte: Adaptado de Osterwalder e Pigneur (2010)

\section{CONSIDERAÇÕES FINAIS}

Neste artigo, a proposta foi identificar as dimensões do modelo de negócio, tomando como base o Canvas Business Model, da empresa ALFA Combustíveis para atuação no Complexo Industrial Portuário de Suape/PE. Os objetivos específicos eram compreender as características do modelo de negócios acerca do bloco constitutivo oferta, do bloco constitutivo infraestrutura e do bloco constitutivo clientes.

Em relação ao bloco oferta de valor, esta organização busca oferecer aos seus clientes já conveniados e aos potenciais clientes um grau de flexibilidade na prestação de serviço, atendimento personalizado com enfoque na resolução de problemas pontuais com os postos revendedores de sua rede e garantia de qualidade do produto que comercializa por meio dos laboratórios móveis (uma equipe de controle de qualidade), que visitam com frequência os postos conveniados, a fim de realizar os testes necessários com os combustíveis. Além 


\section{FutureJournal}

\section{FUTURE STUDIES RESEARCH JOURNAL:}

TRENDS AND STRATEGIES
Profuturo: Programa de Estudos do Futuro Editor Científico: James Terence Coulter Wright Avaliação: Double Blind Review, pelo SEER/OJS Revisão: Gramática, normativa e de layout

Recebido em: 08/10/2015 Aprovado em: 31/10/2016

desses aspectos, a empresa ALFA Combustíveis acaba destacando-se no mercado em função dos limites de crédito, prazos e condições de pagamento que concede aos interessados em comprar os combustíveis que comercializa, bem como participar da rede de postos conveniados.

$\mathrm{Na}$ pesquisa revelou-se que, em relação ao bloco infraestrutura, no que se refere às atividades-chave, a empresa possui as rotinas de logística, as rotinas de faturamento, os processos de vendas e o controle de qualidade necessários para esse tipo de segmento. Os recursos-chave ficam evidenciados pela empresa ALFA Combustíveis por meio de estrutura adequada para operar as frotas de caminhões para entrega dos combustíveis aos clientes e um alto grau de alinhamento entre os departamentos da empresa em relação às atividades executadas na base de operação. No que tange à questão de parcerias, essa distribuidora não estabelece com muita frequência acordos com outras empresas do segmento. Contudo, firma acordos específicos com transportadoras, com profissionais autônomos, com o próprio terminal onde está operando e desenvolve algumas atividades em conjunto com os clientes que ostentam a marca ALFA. Acerca da estrutura de custos, a empresa busca desenvolver uma política de controle em razão de lidar com custos voltados ao armazenamento, aos custos de aquisição dos combustíveis, aos custos das atividades de vendas e, principalmente, aos custos relativos à estrutura e às instalações.

O bloco clientes apresentou, em relação ao relacionamento, o desenvolvimento de dois softwares, com a finalidade de estreitar a relação com os clientes no que diz respeito à realização de pedidos, acompanhamento de entrega dos produtos e apoio aos postos revendedores bandeirados. Dessa forma, a empresa utiliza como canais o acesso ao sistema intranet e um programa que denomina de Entrega nota 10 visando melhorar a eficiência em levar os combustíveis aos clientes no prazo estabelecido nos sistemas da organização. Quanto ao segmento, a empresa ALFA Combustíveis atua basicamente com postos revendedores. Eles podem ser bandeirados (detêm a marca da empresa) ou não bandeirados (marca própria); além desse segmento, a distribuidora também comercializa seus produtos com empresas do segmento automotivo, algumas indústrias e transportadoras. Portanto, as receitas da 


\section{FutureJournal}

empresa do estudo são oriundas não só das vendas de gasolina, etanol e diesel, como também dos acordos firmados com clientes bandeirados para operar com a sua marca.

No campo das recomendações, uma pesquisa sobre os principais agentes do segmento de distribuição de combustíveis teria uma contribuição acadêmica interessante, porque envolveria uma visão mais abrangente das operações desse tipo de empresa. Dentre as limitações, esta pesquisa não aborda o bloco constitutivo viabilidade financeira, o que constitui, portanto, uma possibilidade para a realização de pesquisas futuras, e não permite maiores generalizações já que, restringindo-se a uma única empresa, reflete tão somente a realidade dessa organização.

\section{REFERÊNCIAS}

Amit, R., \& Zott, C. (2001). Value creation in e-business. Strategic Management Journal, 22(6-7), 493-520.

Anderson, J. C., Narus, J. A., \& Van Rossum, W. (2006). Customer value propositions in business markets. Harvard Business Review, 84(3), 90-99.

Baden-Fuller, C., \& Morgan, M. S. (2010). Business models as models. Long Range Planning, 43(2-3), 156-171. 


\section{FutureJournal}

Berghman, L., Matthyssens, P., \& Vandenbempt, K. (2012). Value innovation, deliberate learning mechanisms and information from supply chain partners. Industrial Marketing Management, 41(1), 27-39.

Bertrand, F., Disle, C., Gonthier-Besacier, N., Périer, S., \& Protin, P. (May, 2012). Business model et information financière. Comptabilités et innovation. $1-26$.

Flores, J. G. (1994). Análisis de datos cualitativos - aplicaciones a la investigación educativa. Barcelona: PPU.

Godoy, A. S. (1995). Introdução à pesquisa qualitativa e suas possibilidades. Revista de Administração de Empresas, 35(2), 57-63.

Grönroos, C. (2011). A service perspective on business relationships: the value creation, interaction and marketing interface. Industrial Marketing Management, 40(2), 240-247.

Haas, A., Snehota, I., \& Corsaro, D. (2012). Creating value in business relationships: the role of sales. Industrial Marketing Management, 41(1), 94105.

Itami, H., \& Nishino, K. (2010). Killing two birds with one stone. Long Range Planning, 43(2-3), 364-369.

Lecocq, X., Demil, B., \& Warnier, V. (2006). Le business model, un outil d'analyse stratégique. L'Expansion Management Review, 123(4), 96-109.

Magretta, J. (2002). Why business models matter. Harvard Business Review, $80(5), 86-92$.

Merriam, S. (1998). Qualitative research and case study applications in education (2nd ed.). San Francisco: Jossey Bass.

Merriam, S. (2009). Qualitative research: a guide to design and implementation. San Francisco: John Wiley \& Sons.

Möller, K. E. K., \& Törrönen, P. (2003). Business suppliers' value creation potential. Industrial Marketing Management, 32(2), 109-118.

Morris, M., Schindehutte, M., \& Allen, J. (2005). The entrepreneur's business model: toward a unified perspective. Journal of Business Research, 58(6), 726-735.

Nourse, H. O., \& Roulac, S. (1993). Linking real estate decisions to corporate strategy. Journal of Real Estate Research, 8(4), 475-494. 


\section{FutureJournal}

Osterwalder, A. (2006). How to describe and improve your business model to compete better. IBM Global CEO Study (pp. 1-23), Geneva, Switzerland: IBM.

Osterwalder, A., \& Pigneur, Y. (2010). Business model generation. New Jersey: John Wiley \& Sons.

Penrose, E. T. (1959). The theory of the growth of the firm. New York: John Wiley \& Sons.

Porter, M. E. (1998). Competitive advantage: creating and sustaining superior performance (2nd ed.). New York: Free Press.

Richardson, R. J. (1999). Pesquisa social: métodos e técnicas. São Paulo: Atlas.

Ritter, T., \& Walter, A. (2012). More is not always better: the impact of relationship functions on customer-perceived relationship value. Industrial Marketing Management, 41(1), 136-144.

Shafer, S. M., Smith, H. J., \& Linder, J. C. (2005). The power of business models. Business Horizons, 48(3), 199-207.

Sindicato Nacional das Empresas Distribuidoras de Combustíveis e de Lubrificantes - Sindicom. Combustíveis, lubrificantes e lojas de conveniência - Anuário 2015. Recuperado em 12 de julho, 2015, de http://www.sindicom.com.br/download/anuario_sindicom_2015_ENG_cmyk_fi nal_6.pdf

Stabell, C. B., \& Fjeldstad, Ø. D. (1998). Configuring value for competitive advantage: on chains, shops, and networks. Strategic Management Journal, 19(5), 413-437.

Teece, D. J. (2007). Explicating dynamic capabilities: the nature and microfoundations of (sustainable) enterprise performance. Strategic Management Journal, 28(13), 1319-1350.

Teece, D. J. (2010). Business models, business strategy and innovation. Long Range Planning, 43(2-3), 172-194. 